\title{
DIVERSIFICAÇÃO AGRÍCOLA NA BACIA HIDROGRÁFICA DO RIO DAS CONTAS, BAHIA
}

Elena Beatriz Piedra-Bonilla ${ }^{1}$ Dênis Antônio da Cunha² Marcelo Josè Braga ${ }^{3}$

Resumo: O objetivo principal deste artigo foi descrever e analisar a adoção de mecanismos de diversificação agrícola dos agricultores da bacia hidrográfica do Rio das Contas, Bahia. Foram calculados três índices de diversidade agrícola: Margalef, Shannon e Herfindahl. Ademais, foram analisados os determinantes socioeconômicos da diversificação agrícola por meio de um modelo econométrico Tobit. Os resultados mostraram que a maioria dos agricultores depende da renda obtida com agricultura e/ou pecuária, havendo pouca diversificação fora da propriedade. Além disso, a maioria dos agricultores diversifica suas atividades dentro do estabelecimento, mas os índices calculados indicam que essa diversificação ainda é baixa. Por último, o acesso a linhas de créditos e assistência técnica e o fato de morar na propriedade influenciam positivamente na diversificação de cultivos.

Palavras-chave: Diversificação agrícola. Diversificação de culturas. Renda não agrícola. Renda agrícola. Tobit.

\section{AGRICULTURAL DIVERSIFICATION IN RIO DAS CONTAS RIVER BASIN, BAHIA STATE, BRAZIL}

Abstract: The main objective of this article was to describe and analyze the adoption of agricultural diversification mechanisms for farmers in the Rio das Contas River Basin, Bahia. Three indices of agricultural diversity were calculated: Margalef, Shannon and Herfindahl. In addition, the socioeconomic determinants of agricultural diversification were analyzed through a Tobit econometric model. The results show that the majority of farmers depend on the income obtained from agriculture and/or livestock, with little off-farm diversification. In addition, most farmers diversify on-farm. However, the calculated indices indicate that this diversification is still low. Finally, access to credit and technical assistance and the fact of living on the property influence positively crop diversification.

Keywords: Agricultural diversification. Crop diversification. Off-farm income. On-farm income. Tobit.

\section{DIVERSIFICACIÓN AGRÍCOLA EN LA CUENCA HIDROGRÁFICA DE RIO DAS CONTAS, ESTADO DE BAHIA, BRASIL}

Resumen: El principal objetivo de este artículo fue para describir y analizar la adopción de los mecanismos de diversificación agrícola para los agricultores de la

\footnotetext{
1 Universidade Federal de Viçosa, Departamento de Economia Rural, Viçosa - MG, Brasil, elena.bonilla@ufv.br, https://orcid.org/0000-0003-0387-9260

2 Universidade Federal de Viçosa, Departamento de Economia Rural, Viçosa - MG, Brasil, denis.cunha@ufv.br, http://orcid.org/0000-0003-4838-3795

3 Universidade Federal de Viçosa, Departamento de Economia Rural, Viçosa - MG, Brasil, mjbraga@ufv.br, https://orcid.org/0000-0002-8161-405X
} 
cuenca Río das Contas, Bahía. Fueron calculado tres índices de agricultura de diversidad: Margalef, Shannon y Herfindahl. Además, se analizaron los determinantes socioeconómicos de la diversificación agrícola a través del modelo econométrico Tobit. Los resultados muestran que la mayoría de los agricultores dependen de los ingresos obtenidos de la agricultura y de la pecuaria, con poca diversificación fuera de la propiedad. La mayoría de los agricultores diversifican dentro del establecimiento. Sin embargo, los índices calculados indican que esta diversificación es todavía baja. Por último, el acceso al crédito, la asistencia técnica y el hecho de morar en la propiedad influencian positivamente de la diversificación.

Palabras clave: Diversificación agrícola. Diversificación de cultivos. Ingreso noagrícola. Ingreso agrícola. Tobit.

\section{Introdução}

A diversificação agrícola implica a combinação de várias atividades realizadas pelos agricultores. Suas diferentes formas ajudam na redução da variabilidade da renda do agricultor, no melhoramento na produtividade de recursos escassos e na promoção de sistemas agrícolas ambientalmente sustentáveis (NGUYEN, 2017; JOSHI, 2004; JOSHI et al., 2004). Portanto, a diversificação é reconhecida como importante estratégia na gestão de riscos agrícolas relacionados às condições de produção ou de mercado e também a mudanças climáticas.

Em relação aos riscos relacionados com a variabilidade do clima, a diversificação é um mecanismo que tem potencial de reduzir impactos negativos na produtividade ou renda agrícola. A literatura indica que a diversificação de culturas e/ou de trabalho constitui uma estratégia de adaptação nos sistemas agrícolas (ASFAW, PALLANTE, PALMA, 2018; ASRAVOR, 2017; WELDEGEBRIEL, PROWSE, 2017; THAMO et al., 2017; MITTER, HEUMESSER, SCHMID, 2015; BELOW et al., 2010). Conforme Asfaw, Pallante e Palma (2018), a diversificação tem impactos de bem-estar positivos e significativos quando as famílias mais vulneráveis dependem dela como uma estratégia de adaptação à variabilidade climática de médio prazo. Além disso, a diversificação melhora a sustentabilidade a longo prazo dos sistemas de cultivo, pois ajuda a reduzir o uso de diversos insumos (pesticidas, fertilizantes, água) e limita os danos ao meio ambiente, ligados a seu uso excessivo (MEYNARD et al., 2013).

Assim, a diversificação torna-se tema importante para o Brasil, já que o agronegócio responde por parcela expressiva do Produto Interno Bruto (PIB), aproximadamente, 22\%. (CENTRO DE ESTUDOS AVANÇADOS EM ECONOMIA APLICADA - CEPEA, 2015). Ademais, o país tem grande superfície agrícola em 
diferentes zonas agroecológicas, o que permite ter ampla agrobiodiversidade. Desse modo, trata-se de discussão que deve ser feita em âmbito regional, já que as diferentes regiões têm expectativas de impactos diferenciados com a mudança climática.

O Nordeste é uma região brasileira para a qual são esperados impactos mais severos causados por mudanças climáticas (MAGRIN et al., 2014) e que já vem passando por sérios problemas relacionados ao clima. Segundo Marengo et al. (2017), a seca que afeta essa região nos últimos anos apresenta intensidade e impacto não observados em várias décadas na economia e sociedade regionais, sendo a agricultura de subsistência regional a mais afetada negativamente. Ao mesmo tempo, no Nordeste está um dos estados com maior diversificação de cultivos agrícolas do Brasil, o estado de Bahia, que se destaca pela diversificação agrícola (44 culturas), que pode reduzir a vulnerabilidade que a região Nordeste apresenta. Os dados da Pesquisa Agrícola Municipal (Instituto Brasileiro de Geografia e Estatística - IBGE, 2016) indicam que a Bahia ficou em quarto lugar em termos de número de culturas cultivadas, estando atrás nesse quesito apenas dos estados do Paraná (49 culturas), de São Paulo (47 culturas) e de Minas Gerais e Rio Grande do Sul (46 culturas).

Nesse sentido, o trabalho busca compreender a questão da diversificação na região da bacia hidrográfica do Rio das Contas, no estado da Bahia, dado seu perfil eminentemente agrícola. A bacia hidrográfica, como unidade de estudo, possibilita uma visão sistêmica, que analisa a natureza socioeconômica do espaço em conjunto com fatores edafoclimáticos (DE LIMA, 2010). Dessa forma, o estudo pode levar a políticas públicas para melhorar o desempenho regional.

A pesquisa tem dois objetivos principais: primeiramente, procura-se descrever e analisar a adoção dos mecanismos de diversificação, usando as abordagens socioeconômica e agrícola dos agricultores da Bacia Hidrográfica do Rio das Contas, Bahia; em seguida, são analisados os determinantes socioeconômicos da diversificação de culturas.

Assim, na segunda parte do artigo, são apresentadas as principais abordagens e mecanismos de diversificação agrícola, posteriormente é descrito o modelo econômico de escolha de diversificação de culturas. Na quarta parte, é explicada a metodologia utilizada para atingir os objetivos. Na quinta seção, são apresentados os resultados obtidos pela pesquisa de campo. Finalmente, são apresentadas as considerações finais. 


\section{Abordagens e mecanismos de diversificação agrícola}

$\mathrm{Na}$ escala de estabelecimentos agrícolas, a diversificação tem duas principais abordagens. Primeiramente, pode-se falar da abordagem socioeconômica, na qual é considerada a existência de rendas agrícolas e não agrícolas (pluriatividade), a realização de duas ou mais atividades agrícolas ou pecuárias na mesma propriedade e a implementação, simultânea ou sucessiva, de várias atividades agrícolas e não agrícolas, que se complementam (ELLIS, 2000; JOSHI, 2004). Ao mesmo tempo, existe a abordagem agrícola (diversidade agrícola), que contempla a diversificação de espécies agropecuárias, a diversificação genética dentro das espécies agrícolas (a variabilidade de indivíduos da mesma espécie) e a diversificação de agroecossistemas (sistemas de manejo agropecuários dependendo do ecossistema) (BROOKFIELD, STOCKING, 1999; SANTILLI, 2009).

Logo, a diversificação precisa ser analisada sob a ótica das duas abordagens, já que as questões agrícolas afetam os resultados socioeconômicos e vice-versa. A Tabela 1 procura integrar essas duas abordagens e mostrar todas as diversas atividades que os agricultores desenvolvem dentro e fora do estabelecimento, relacionadas ou não com a agropecuária. Assim, pode-se observar que os agricultores têm amplo portfólio de estratégias para lidar com os riscos econômicos e climáticos.

As atividades fora do estabelecimento estão ligadas ao conceito de pluriatividade, que permite a compreensão dos agricultores numa realidade mais complexa, ultrapassando os limites de sua propriedade. Segundo Schneider (2001), a pluriatividade é entendida como uma estratégia utilizada nos estabelecimentos agrícolas que operam fundamentalmente com base no trabalho familiar, em que algum membro da família articula com o mercado de trabalho agrícola ou não agrícola. Destarte, os agricultores familiares podem estabelecer iniciativas de diversificação das suas ocupações interna e externamente à sua propriedade e aumentar as fontes e as formas de acesso à renda (SCHNEIDER, 2007).

Por outro lado, as atividades dentro do estabelecimento estão separadas entre agrícolas e não agrícolas. No primeiro caso, as atividades estão relacionadas ao conceito de agro-biodiversidade, definido como a variedade e a variabilidade de animais, plantas e microrganismos, que são, direta ou indiretamente, utilizados para a alimentação e a agricultura, incluindo cultivos, pecuária, silvicultura e pesca (FAO, 
1999; SANTILLI, 2009). Neste estudo, faz-se referência somente às espécies diretamente utilizadas para a agricultura, com interesse econômico. Desse modo, levando em consideração os níveis de variabilidade da biodiversidade, há a diversificação de espécies, que pode ser vegetal e animal, a diversidade genética (variedades de espécies vegetal e animal) e a diversidade de agroecossistemas ${ }^{4}$ (SANTILLI, 2009). Já as atividades não agrícolas são aquelas que, de forma sucessiva ou simultânea, complementam as atividades agrícolas, como, por exemplo, serviços de turismo, de alimentação ou ambientais.

Tabela 1- A diversificação dentro e fora do estabelecimento agrícola

\begin{tabular}{|c|c|c|}
\hline & $\begin{array}{l}\text { Atividades dentro do } \\
\text { estabelecimento agrícola }\end{array}$ & $\begin{array}{c}\text { Atividades fora do } \\
\text { estabelecimento agrícola } \\
\text { (Pluriatividade) }\end{array}$ \\
\hline Atividades agrícolas & $\begin{array}{l}\text {-Diversificação de espécies } \\
\text { agropecuárias } \\
\text {-Diversificação de variedades } \\
\text { da mesma espécie } \\
\text {-Diversificação de } \\
\text { agroecossistemas }\end{array}$ & -Trabalho assalariado agrícola \\
\hline $\begin{array}{l}\text { Atividades não } \\
\text { agrícolas }\end{array}$ & $\begin{array}{l}\text {-Serviços rurais (serviços de } \\
\text { turismo, de alimentação) }\end{array}$ & $\begin{array}{l}\text {-Trabalho assalariado ou } \\
\text { autônomo não agrícola }\end{array}$ \\
\hline
\end{tabular}
Fonte: Elaboração própria dos autores.

A diversificação de culturas é uma forma de melhorar a viabilidade a longo prazo da agricultura, melhorando a rentabilidade e a estabilidade do setor, já que os impactos positivos estão ligados à renda e à produção geral (JOSHI, 2004). Para ilustrar, a rotação de arroz com outros cultivos sempre dá melhor renda do que somente o cultivo de arroz no Vietnam (MINOT et al., 2006). Similarmente, na China, estudos com estabelecimentos agrícolas que diversificam com vegetais de alto valor longe da monocultura de arroz mostram que podem melhorar sua renda (VAN DEN BERG et al, 2007). Adicionalmente, resultados para o Brasil indicam que a Integração Lavoura-Pecuária tem papel importante na intensificação do uso da terra, com grande potencial para elevação dos níveis de produtividade das lavouras e da pecuária na região Nordeste do Mato Grosso (FRANCHINI et al., 2010).

\footnotetext{
4 Ecossistemas que são usados para agricultura com processos similares, com componentes, interações e funções similares, consistindo em policultivos, monocultivos, sistemas mistos que incluem sistemas agropecuários, agroflorestais, sistemas lavoura-pecuária-floresta.
} 
Além disso, a diversificação de culturas também possibilita que os sistemas agrícolas sejam ambientalmente sustentáveis. Por exemplo, a rotação ou alternância da produção entre culturas e pecuária tem o potencial de reduzir a erosão do solo, melhorar a umidade e a retenção de nutrientes (DELCOURT \& VAN KOOTEN, 1995). Adicionalmente, a associação entre leguminosas e cereais melhora a fertilidade do solo, pois as leguminosas têm a capacidade de fixar o nitrogênio atmosférico no solo.

Em relação à supressão de pragas, os sistemas agrícolas diversificados, com maior quantidade de riqueza de espécies de cultivos distribuídos no espaço e no tempo, são mais similares aos sistemas naturais e, assim, mantêm maior diversidade de espécies de animais, de forma que muitos deles podem ser inimigos naturais das pragas dos cultivos (ALTIERI, 1999; LIN, 2011). Além disso, o aumento de diversidade genética na produção de cultivos diminui a susceptibilidade a doenças, porque tem taxa menor de transmissão/contágio (LIN, 2011). Assim, a diversificação de culturas permite tanto melhorar a sustentabilidade agrícola quanto reduzir o uso de insumos para fertilização do solo e controle de doenças e pragas.

\section{Modelo de escolha de diversificação de culturas}

Para examinar os determinantes da diversificação de culturas, é apresentado um modelo geral de produção agrícola desenvolvido por Van Dusen (2000) e Benin et al. (2004). O agricultor maximiza sua utilidade sobre um conjunto de bens de consumo $\left(\mathrm{C}_{\mathrm{P}}\right)$ gerados na propriedade agrícola e um conjunto de bens de consumo comprados $\left(\mathrm{C}_{\mathrm{NP}}\right)$ com a renda agrícola ou não agrícola. $A$ utilidade é afetada por um vetor de características socioeconômicas do agricultor $\left(\phi_{A}\right)$ (VAN DUSEN; 2000; BENIN et al., 2004):

$$
\max _{C_{P}, C_{N P}} U\left(C_{p}, C_{N p}, \phi_{A}\right)
$$

O consumo da família está sujeito a uma restrição de renda que abrange a renda da produção de produtos não consumidos $\left(Q-C_{P}\right)$ de um vetor $Q$ dos produtos agrícolas e a renda não agrícola $\bar{Y}$ (VAN DUSEN; 2000; BENIN et al., 2004). A produção agrícola está sujeita a uma função de tecnologia fixa, que combina insumos $(\mathrm{X})$ entre $j$ culturas, estando o lucro sujeito aos preços de insumos e produtos (VAN DUSEN; 2000). 
$p_{p}\left(Q-C_{p}\right)-p_{x} X+\bar{Y}=p_{N P} C_{N P}$

A produção está em função de um vetor de características agroecológicas e tecnológicas (tais como tamanho, tipo de solo, bioma, irrigação) do estabelecimento agrícola $\left(\phi_{E A}\right)$ (VAN DUSEN; 2000; BENIN et al., 2004):

$Q=f\left(\alpha, X \mid \phi_{A}, \phi_{E A}\right)$

Cada conjunto de proporção da área $\left(\alpha_{j}\right)$ entre $j$ culturas soma $1, \Sigma_{j}^{J} \alpha_{j}=1, j=$ $1,2, \ldots, J$, que projeta no vetor $Q$ através de relações físicas de insumo-produto. A escolha da proporção da área implica um nível de produtos $^{5}$ do estabelecimento e vice-versa (BENIN et al., 2004).

Segundo Benin et al. (2004), a função objetivo da equação (1) pode ser reescrita como:

$$
\max _{h} U\left(C_{p}, C_{N p}, \phi_{A}\right)
$$

em que $\mathrm{h}=\left(\left(\alpha_{1}, \ldots \alpha_{j}\right) \geq 0 ; C_{f}, c_{n f}, X\right)$. Não há soluções interiores para cada cultura, e algumas proporções de área podem ser censuradas como zero.

A escolha de produção e de consumo pelo produtor e feita simultaneamente quando os mercados de insumos e produtos são imperfeitos (BENIN et al., 2004), ou seja, existem produtores que conseguem influenciar o preço de mercado. Logo, os preços são endógenos ao estabelecimento agrícola, como também são afetados pelos custos de transações de mercado (BENIN et al., 2004), dados por isolamento geográfico dos principais mercados ou infraestrutura rodoviária (VAN DUSEN; 2000). Sendo assim, esses custos de transação e o acesso ao mercado são caracterizados por um vetor de características exógenas de mercado $\left(\phi_{M}\right)$, que, de forma geral, descreve as restrições de mercado ao produtor (VAN DUSEN; 2000).

Conforme Benin et al. (2004), quando as escolhas de consumo e produção não são separadas, a escolha ótima do agricultor $\left(h^{*}=\left(\alpha^{*}, C_{f}^{*}, C_{n f}^{*}, X^{*}\right)\right.$ pode ser definida como função de forma reduzida de renda não agrícola, das características do agricultor, do estabelecimento agrícola e do mercado:

$$
h^{*}=h^{*}\left(\bar{Y}, \phi_{A}, \phi_{E A}, \phi_{M}\right)
$$

A equação (5) afeta o consumo e a produção e, consequentemente, influencia o nível de diversificação de culturas nos estabelecimentos agrícolas.

\footnotetext{
${ }^{5}$ A produção pecuária não é contemplada, mesmo que exista demanda derivada das culturas para requerimentos de alimentação e forragem (BENIN et al., 2004).
} 
Por outro lado, a diversificação de culturas $(D)$ de cada estabelecimento agrícola $i$ toma a forma de uma demanda derivada simples (BENIN et al., 2004; RAHMAN, 2008; VAN DUSEN, 2000):

$$
D=D\left(\alpha_{j}^{*}\left(\bar{Y}, \phi_{A}, \phi_{E A}, \phi_{M}\right)\right.
$$

A equação (6) é o resultado da otimização da utilidade do agricultor. Além disso, esta equação também é considerada diversificação latente de culturas (índice de diversidade) (VAN DUSEN, 2000).

\section{Metodologia}

\section{Modelo empírico dos determinantes da escolha de culturas}

O referencial teórico apresentado fundamenta a seguinte estrutura geral do modelo econométrico a ser estimado:

$D_{i}=a+b \bar{Y}_{i}+c \phi_{A i}+d \phi_{E A i}+e \phi_{M i}+\varepsilon_{i}$,

em que $D_{\bar{i}}$ representa o índice de diversificação do produtor $i, \bar{Y}$ é a renda não agrícola, $\phi_{A}$ é o vetor das características do agricultor, $\phi_{E A}$ é o vetor das características do estabelecimento agrícola, $\phi_{M}$ é o vetor das características de mercado $\mathrm{e} \varepsilon$ é o termo de erro dos fatores não observado e/ou ruído aleatório. Os parâmetros a ser estimados são $a, b, c, d$ e $e$.

Nessa pesquisa, serão calculados três diferentes índices de diversificação agrícola. Portanto, $D_{i}$ é um escalar construído pelo vetor das partes de superfície atribuídas às culturas. Os índices mais conhecidos ligados à diversificação de cultivos são o índice de concentração de culturas (Herfindahl), o índice de riqueza de culturas (Margalef) e o índice de regularidade (combinação de riqueza e abundância) de culturas (Shannon). O índice Herfindahl é adaptado do índice de concentração de mercados, enquanto os dois últimos são adaptados dos índices ecológicos de diversidade espacial em espécies para representar regularidade ou riqueza na diversificação de culturas (BENIN et al., 2004; RAHMAN, 2008). A definição desses índices encontra-se na Tabela 2.

\section{Tabela 2 - Definição dos índices de diversificação de cultivos}

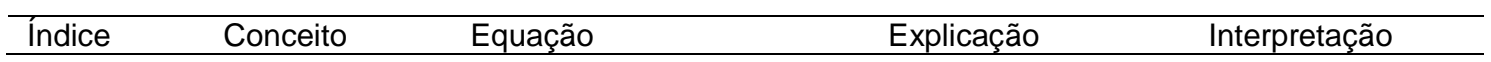




\begin{tabular}{|c|c|c|c|c|}
\hline Margalef & $\begin{array}{l}\text { Riqueza } \\
\text { (número de } \\
\text { cultivos } \\
\text { encontrados) }\end{array}$ & $D_{M}=(S-1) / \ln A_{\mathbb{i}_{x}} D_{M} \geq 0$ & $\begin{array}{l}\mathrm{A}_{\mathrm{i}}=\text { superfície total } \\
\text { plantada para todas } \\
\text { as culturas do } \\
\text { estabelecimento } \\
\text { agrícola, } S \text { é o } \\
\text { número de cultivos. }\end{array}$ & $\begin{array}{l}\text { Valores maiores } \\
\text { indicam maior } \\
\text { diversificação }\end{array}$ \\
\hline \multirow[t]{2}{*}{ Shannon } & $\begin{array}{l}\text { Regularidade } \\
\text { (combinação } \\
\text { de riqueza e } \\
\text { uniformidade) }^{6}\end{array}$ & $D_{s}=-\sum_{j=1}^{N} \alpha_{j}-\ln \alpha_{j}, D_{s} \geq 0$ & $\begin{array}{l}\alpha_{\mathrm{j}}=\text { proporção da } \\
\text { superfície ocupada } \\
\text { pelo cultivo } j^{2} \text { em }\end{array}$ & $\begin{array}{l}\text { Valores maiores } \\
\text { indicam maior } \\
\text { diversificação }\end{array}$ \\
\hline & & (9) & $A_{\overline{1}}$. & \\
\hline Herfindahl & Concentração & $D_{H}=\sum_{j=1}^{N} \alpha_{j}^{2}, 0 \leq D_{H} \leq 1$ & $\begin{array}{l}\alpha_{\mathrm{i}}=\text { proporção da } \\
\text { superfície ocupada } \\
\text { pelo cultivo } \tilde{\mathrm{j}}^{\mathrm{a}} \mathrm{em} \\
\mathrm{A}_{\mathrm{i}} \text {. }\end{array}$ & $\begin{array}{l}\text { O valor de zero } \\
\text { indica } \\
\text { diversificação } \\
\text { perfeita e o valor } \\
\text { de } 1 \text { indica } \\
\text { perfeita } \\
\text { especialização } \\
\text { (um único cultivo) }\end{array}$ \\
\hline
\end{tabular}

Fonte: Adaptado de Benin et al. (2004); Islam e Rahman (2012) e Rahman (2008).

As variáveis independentes são medições dos vetores mostrados na parte direita da equação (7), definidas na Tabela 3. A renda não agrícola pode ter efeitos ambíguos, já que ajudaria na compra de insumos que podem afetar tanto na intensificação de culturas, quanto na diversificação das atividades agrícolas. A idade pode ter efeitos ambíguos, já que agricultores mais jovens estão mais dispostos a investir em diferentes cultivos, enquanto agricultores mais velhos podem ter menos disposição para esse tipo de experiência (BENIN et al., 2004), ao mesmo tempo, agricultores com maior idade podem conservar a diversidade pela sua experiência e pelas suas práticas tradicionais (VAN DUSEN, 2000).

\section{Tabela 3 - Definição das variáveis explicativas, unidades de medida, sinal esperado, resumo estatístico}

\begin{tabular}{lllllcc}
\hline Variável & Descrição & & Unidade & Média & $\begin{array}{c}\text { Desvio } \\
\text { padrão }\end{array}$ & $\begin{array}{c}\text { Sinal } \\
\text { esperado }\end{array}$ \\
\hline $\begin{array}{l}\text { Renda não agrícola } \\
(\bar{Y})\end{array}$ & $\begin{array}{l}\text { Proporção de renda } \\
\text { agrícola }\end{array}$ & não & Porcentagem & 0,290 & 0,369 & \pm \\
Características do agricultor $\left(\phi_{A}\right)$ & & & & & & \\
Idade & Idade do chefe de família & Anos & 50,525 & 15,273 & \pm
\end{tabular}

\footnotetext{
6 De forma geral, a regularidade descreve a variabilidade na abundância de espécies, mais especificamente, é uma combinação de riqueza e uniformidade. A riqueza de espécies faz referência ao número total de espécies por área ou unidade específica, enquanto a uniformidade indica quão uniformemente os indivíduos são distribuídos entre as diferentes espécies em uma comunidade (MAGURRAN, 2004).
} 


\begin{tabular}{|c|c|c|c|c|c|}
\hline Escolaridade & $\begin{array}{l}\text { Nível de escolaridade do } \\
\text { agricultor }^{7}\end{array}$ & Unidades & 2,954 & 2,067 & \pm \\
\hline Tamanho da família & $\begin{array}{l}\text { Número de membros da } \\
\text { família }\end{array}$ & Unidade & 5,257 & 9,187 & \pm \\
\hline Acesso a Crédito & $\begin{array}{l}\text { Dummy ( } 1 \text { se tem tido acesso } \\
\text { ao crédito, } 0 \text { caso contrário }\end{array}$ & & 0,279 & 0,449 & + \\
\hline Condição legal & $\begin{array}{l}\text { Dummy ( } 1 \text { se é proprietário do } \\
\text { estabelecimento, } 0 \text { caso } \\
\text { contrário }\end{array}$ & & 0,864 & 0,343 & + \\
\hline Moradia & 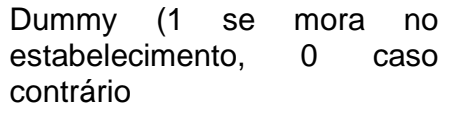 & & 0,643 & 0,480 & + \\
\hline $\begin{array}{l}\text { Assistência técnica } \\
\text { Características do }\end{array}$ & $\begin{array}{l}\text { Dummy (1 se tem tido } \\
\text { assistência técnica, } 0 \text { caso } \\
\text { contrário) } \\
\text { abelecimento agrícola }\left(\phi_{E A}\right)\end{array}$ & & 0,304 & 0,461 & + \\
\hline $\begin{array}{l}\text { Tamanho } \\
\text { estabelecimento }\end{array}$ & $\begin{array}{l}\text { Tamanho por estabelecimento } \\
\text { agrícola }\end{array}$ & $\mathrm{Ha}$ & 31,056 & 68,026 & + \\
\hline Irrigação & $\begin{array}{l}\text { Dummy ( } 1 \text { se tem irrigação, } 0 \\
\text { caso contrário }\end{array}$ & & 0,382 & 0,487 & - \\
\hline $\begin{array}{l}\text { Bioma Caatinga } \\
\text { Características do r }\end{array}$ & $\begin{array}{l}\text { Dummy ( } 1 \text { se o município está } \\
\text { no bioma Caatinga, } 0 \text { caso } \\
\text { contrário } \\
\text { rcado }\left(\phi_{M}\right)\end{array}$ & Número & 0,6982 & 0,466 & - \\
\hline $\begin{array}{l}\text { Densidade } \\
\text { populacional }\end{array}$ & $\begin{array}{l}\text { Densidade populacional do } \\
\text { município }\end{array}$ & $\mathrm{Hab} . / \mathrm{km}^{2}$ & 25,750 & 23,187 & + \\
\hline
\end{tabular}

A variável escolaridade é considerada uma proxy para o acesso à informação, bem como para representar a capacidade de entendimento de aspectos técnicos relacionados a diferentes cultivos, o que poderia afetar positivamente a diversidade de cultivos (RAHMAN, 2008). Para a variável tamanho de família, espera-se efeito positivo sobre a diversificação, porque representa maior capacidade de mão de obra (BENIN et al., 2004) e também de sucessão da atividade agrícola.

A variável assistência técnica é considerada importante recurso de disseminação de informações nas práticas agrícolas (RAHMAN, 2008), podendo influenciar a adoção de novas tecnologias e também a diversificação de culturas. Segundo Benin et al. (2004), os estabelecimentos agrícolas maiores podem produzir maior quantidade de cultivos. A variável irrigação pode diminuir a diversidade através de condições uniformes de umidade (BENIN et al., 2004), bem como ser um investimento direcionado para cultivos intensivos. A dummy Caatinga diz respeito a um dos três biomas, juntamente com a Mata Atlântica e o Cerrado, nos quais os municípios da bacia do Rio das Contas estão localizados. Esse bioma se caracteriza por ter menor precipitação (LEAL et al., 2005), de modo que afetaria

\footnotetext{
7 Os níveis de escolaridade foram os seguintes: analfabeto $=0$; saber ler e escrever $=1$; ensino fundamental incompleto $=2$; ensino fundamental completo $=3$; ensino médio incompleto $=4$; ensino médio completo $=5$; ensino superior incompleto $=6$; ensino superior completo $=7$.
} 
negativamente a diversificação de culturas. A variável densidade populacional implica melhor acesso a mercados, instituições e informação (RAHMAN, 2008), com potencial para afetar positivamente a decisão de diversificar a produção frente a novas demandas de produtos e, igualmente, facilitar o acesso à oferta de insumos, por exemplo, de diferentes sementes.

Para estimar os parâmetros da equação (7), foi utilizado o modelo econométrico Tobit. Esta metodologia é apropriada já que os índices calculados geram observações com valores censurados: os índices de Margalef e Shannon com valor de zero e o índice de Herfindahl com valor de um. Esses valores censurados representam os estabelecimentos especializados em uma única cultura. Assim, o modelo Tobit inclui as observações que estão no limite e acima do limite para estimar uma regressão linear para os índices Margalef e Shannon (RAHMAN, 2008). Para o índice Herfindahl, tem-se o contrário, já que o modelo Tobit inclui as observações com valores no limite (valor de um) e abaixo do limite. Com esse índice, provavelmente nenhum das observações atinge valor de zero, ou seja, diversificação perfeita.

Para os índices de Margalef e Shannon (censura em 0), o modelo estocástico de Tobit pode ser expresso da seguinte forma geral (RAHMAN, 2008):

$$
y_{m}=\left\{\begin{aligned}
X_{m} \beta+u_{m}, & \text { se } X_{m} \beta+u_{m} \\
0, & \text { se } X_{m} \beta+u_{m} \leq 0, m=1,2, \ldots, M
\end{aligned}\right.
$$

Ao mesmo tempo, o modelo estocástico de Tobit para o índice Herfindahl (censura em 1) é o seguinte:

$$
y_{m}=\left\{\begin{aligned}
& X_{m} \beta+u_{m}, \text { se } X_{m} \beta+u_{m}<1 \\
& 0, \text { se } X_{m} \beta+u_{m} \geq 1, m=1,2, \ldots, M
\end{aligned}\right.
$$

em que $M$ é o número de observações, $y_{m}$ é a variável dependente (índices de diversificação), $X_{m}$ é um vetor das variáveis independentes, representando atributos de tecnologia, características do agricultor e do estabelecimento agrícola, $\beta$ é um vetor de parâmetros a ser estimados e $u_{m}$ é um termo de erro distribuído independentemente, assumido normal com média zero e variância constante $\sigma^{2}$. 0 modelo pressupõe índice estocástico igual a $X_{m} \beta+u_{m}$, que é observado quando positivo para os índices Margelef e Shannon e menor que um para o índice Herfindahl, assim qualificando como uma variável latente inobservada (RAHMAN, 2008). A relação entre o valor esperado de todas as observações $E_{y}$ e o valor esperado condicional acima do limite $E_{y}^{*}$ é dada por (RAHMAN, 2008):

$$
E_{y}=F(z) E_{y}^{*}
$$


em que $F(z)$ é a função de distribuição acumulativa de densidade normal e $=X \beta / \sigma$.

\section{Dados}

Os dados para pesquisa foram coletados em 289 propriedades agrícolas da bacia hidrográfica do Rio das Contas, Bahia, no período de setembro a novembro de 2014. Para esta análise, foram eliminadas nove observações que não informaram dados relevantes para as variáveis relevantes na pesquisa. A seleção das unidades de observação foi baseada em amostragem aleatória simples com 95\% de confiança estatística. Foi aplicado um questionário semiestruturado, englobando questões relacionadas: (i) às informações socioeconômicas dos produtores e de suas propriedades (idade, escolaridade, pessoas dependentes da renda agrícola e acesso à assistência técnica, crédito rural); ii) às medidas adaptativas implementadas nas propriedades (uso da terra, produção pecuária, cultivos agrícolas da propriedade, outras fontes de rendas). Detalhes da seleção da amostra bem como do questionário podem ser obtidos em Carlos (2016).

\section{Resultados e discussão}

\section{Perfil socioeconômico e demográfico dos agricultores entrevistados}

A Figura 1 mostra as principais características socioeconômicas e demográficas dos agricultores entrevistados. Pode-se observar que os agricultores, em sua maioria (81\%), são casados. Além disso, mais da metade (61\%) das famílias na amostra tem entre um e quatro membros dependentes da renda agrícola, sendo de cinco pessoas a média de dependentes da propriedade. Adicionalmente, observa-se que ao redor do 3\% das propriedades não têm pessoas dependentes da renda agrícola, como também aproximadamente $6 \%$ dos agricultores têm mais de dez indivíduos que dependem da propriedade. O número de pessoas dependentes da propriedade serve como uma proxy para analisar a influência do tamanho da família nas práticas de adaptação. Segundo Deressa et al. (2009), quanto maior o tamanho da família, maior a probabilidade de se adaptar às mudanças climáticas. Assim, considera-se que as famílias com muitos membros aumentem a diversificação dentro e fora do estabelecimento agrícola porque representam mais 
capacidade de mão de obra e também maior possibilidade de sucessão da propriedade.

\section{Figura 1. Características socioeconômicas e demográficas dos agricultores entrevistados}

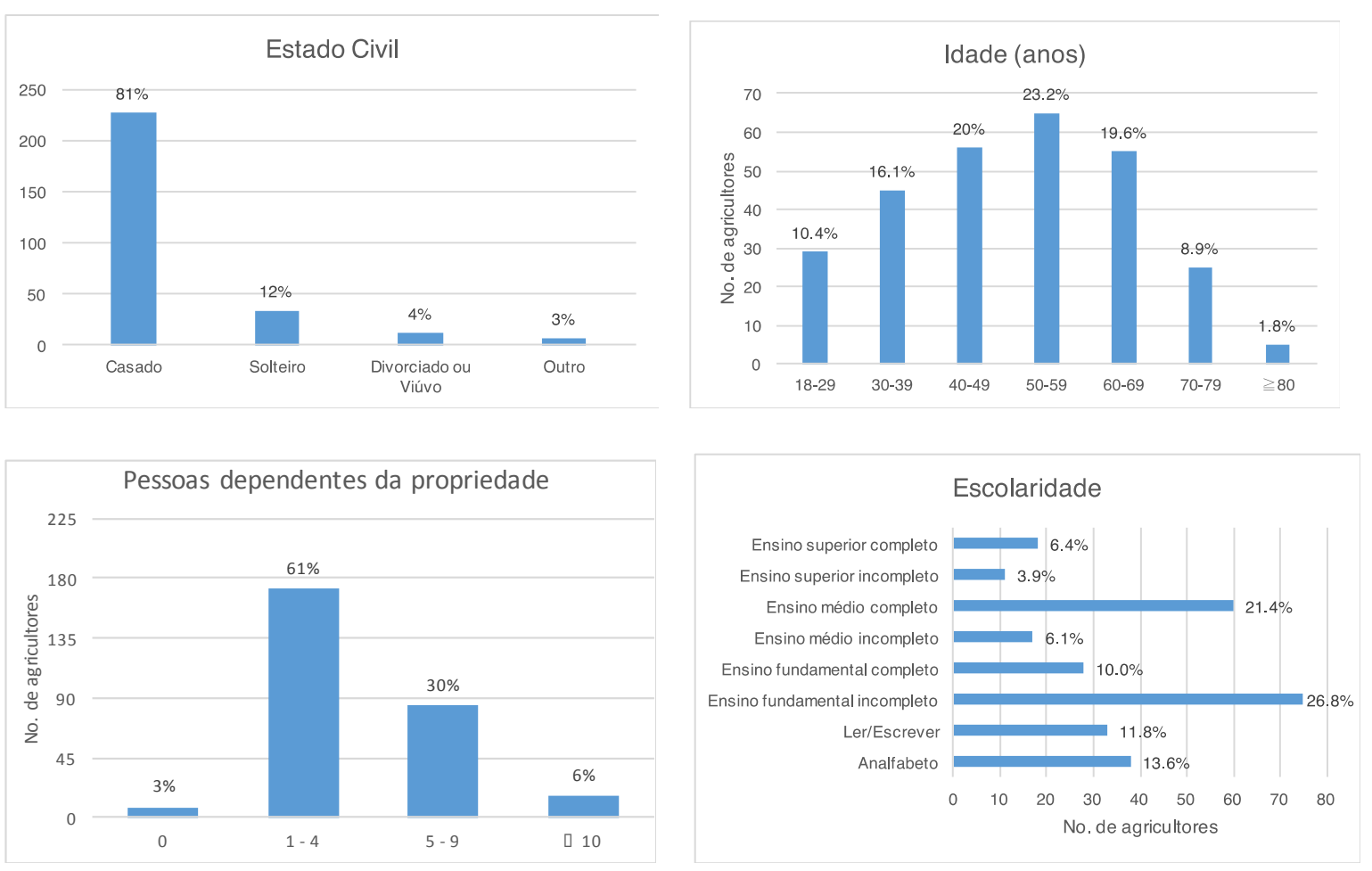

Fonte: Dados da pesquisa.

A média de idade dos agricultores é de 51 anos, sendo que a maioria (70\%) tem menos de 60 anos, ou seja, fazem parte da população economicamente ativa. Conforme Cunha et al. (2015), quanto maior a idade, maior a experiência acumulada nas suas atividades, havendo, consequentemente, mais chance de adoção de estratégias adaptativas. No entanto, no que diz respeito à diversificação agrícola, produtores mais jovens estão mais dispostos a tentar novas atividades ou produções, contrariamente aos agricultores com idade mais avançada (BENIN et al., 2004).

Em relação à educação, a maioria dos agricultores tem baixo nível educacional, já que ao redor de $27 \%$ dos entrevistados têm Ensino Fundamental incompleto e 25,4\% não receberam educação formal e somente sabem ler e escrever ou são analfabetos. Essa característica pode prejudicar a adoção de algum mecanismo de diversificação, já que agricultores com maiores níveis de educação têm maior probabilidade de adaptação a mudanças climáticas (DERESSA et al., 
2009). A educação é entendida como proxy para o acesso à informação como também para a capacidade de entendimento (RAHMAN, 2008).

As principais características dos estabelecimentos agrícolas da amostra estão representadas na Figura 2. Em relação ao tamanho da propriedade, a maior parcela $(38,6 \%)$ dos agricultores têm menos de cinco hectares, ou seja, são minifúndios, já que têm uma área inferior a um módulo fiscal ${ }^{8}$ (INCRA, 2013). É possível inferir que, com área tão reduzida, tais agricultores podem ter maior dificuldade de obtenção de retorno financeiro. Ademais, os pequenos produtores têm limitada propensão adaptativa em decorrência de sua reduzida capacidade financeira (CUNHA et al., 2013). Ao mesmo tempo, a queda da renda proveniente das atividades agropecuárias na propriedade pode levar ao desenvolvimento de atividades fora do estabelecimento agrícola (SIMIONI, 2013), o que aumenta a diversificação.

Observa-se que aproximadamente $86 \%$ dos agricultores entrevistados são proprietários dos estabelecimentos agrícolas. A condição legal de propriedade do estabelecimento agrícola representa o patrimônio dos agricultores, o que pode estar vinculado ao desejo de permanência na área rural, consequentemente, levando à procura de diferentes formas de atividades para garantir sua sobrevivência.

Figura 2. Características das propriedades dos agricultores entrevistados

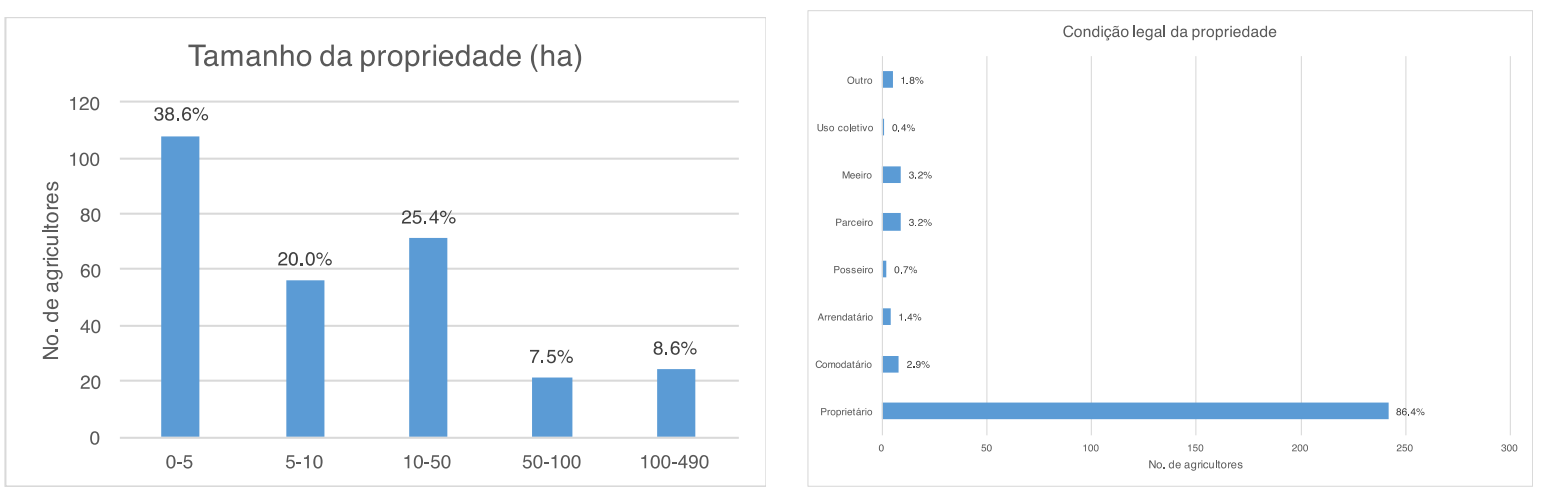

Fonte: Dados da pesquisa

\footnotetext{
8 O módulo fiscal é uma unidade de medida, em hectares, cujo valor é fixado pelo Instituto Nacional de Colonização e Reforma Agrária (INCRA) para cada município do Brasil. Seu valor expressa a área mínima necessária para que uma unidade produtiva seja economicamente viável. A dimensão de um módulo fiscal varia de acordo com o município onde está localizada a propriedade. O valor do módulo fiscal no Estado de Bahia varia de 5 a 65 hectares (INCRA, 2013).
} 
Adicionalmente, cerca de $28 \%$ dos agricultores tiveram acesso ao crédito agrícola no último ano. $\mathrm{O}$ acesso ao crédito pode ser pensado de duas formas em relação aos mecanismos de diversificação. Primeiramente, a restrição ao crédito propicia diversificação de atividades fora do estabelecimento para comprar insumos agrícolas ou fazer compras de equipamentos (ELLIS, 2000). Segundo, o acesso ao crédito possibilita ao produtor alcançar mecanismos de adaptação à mudança climática e permitir a utilização de novas tecnologias, como a diversificação de cultivos ou pecuária. Do mesmo modo acontece com a assistência técnica, considerada importante recurso de disseminação de informação nas práticas agrícolas (RAHMAN, 2008). Na bacia, aproximadamente $70 \%$ dos agricultores não recebem assistência técnica, o que dificulta a adoção de mecanismos de diversificação.

\section{Diversificação com atividades fora do estabelecimento agrícola}

O espaço rural brasileiro não é mais reduzido somente à agricultura, porque há evidência da emergência de atividades não agrícolas ${ }^{9}$. Segundo Del Grossi e Silva (2002 apud SIMIONI, 2013), as atividades não agrícolas mais destacadas no espaço rural são as relacionadas aos serviços, atividades da indústria de transformação, da construção civil, do comércio de mercadorias e serviços sociais (principalmente a educação), sendo o emprego doméstico e a construção civil os dois setores que mais vêm gerando ocupações não agrícolas no Brasil. A região da bacia hidrográfica do Rio das Contas é parte dessa realidade, uma vez que aproximadamente $30 \%$ de seus agricultores têm renda dependente das atividades agropecuárias de menos de 50\% (Figura 3). Não obstante, a região ainda tem longo caminho a percorrer nesse quesito, já que a maioria (55.7\%) dos agricultores tem sua renda completamente dependente da atividade agrícola e/ou pecuária.

\section{Figura 3. Renda dependente da atividade agrícola e/ou pecuária}

\footnotetext{
${ }_{9}^{9}$ De acordo com os dados do Censo Agropecuário 2006, 1.910.131 (37\%) estabelecimentos agropecuários no Brasil e 907.489 (37\%) na região Nordeste podem ser considerados pluriativos (ESCHER et al., 2014).
} 


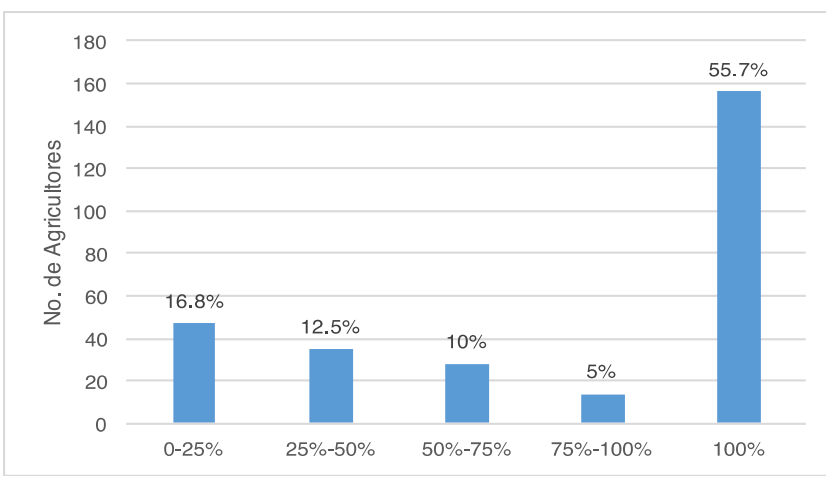

Fonte: Dados da pesquisa

Na bacia hidrográfica do Rio da Contas, as fontes de renda são dependentes do setor primário. De modo geral, espera-se que as oportunidades de obter renda fora do estabelecimento agrícola sejam menores em regiões primordialmente agrícolas, com pouca presença de indústrias, comércio ou prestação de serviços (ESCHER et al., 2014; GLITSOS, 1988 apud DASKALOPOULOU \& PETROU, 2002). Assim, a diversificação dentro do estabelecimento agrícola é mais expressiva, pois a diversificação externa depende do desenvolvimento dos setores secundários e terciários, pouco expressivos na região.

Os resultados da pesquisa indicaram que os agricultores com tamanho de propriedade menor do que 10 hectares, principalmente, dependem completamente da renda agrícola (Figura 4). Além disso, a renda da maioria dos agricultores com mais de 10 hectares depende de outras fontes não ligadas à agricultura. Esses resultados contradizem a suposta relação negativa entre o tamanho da propriedade e a existência de outra atividade fora do estabelecimento (DASKALOPOULOU \& PETROU, 2002). Ao mesmo tempo, esse resultado pode estar relacionado ao fato de 0 maior percentual de estabelecimentos de agricultura não familiar ser classificado como pluriativo em relação à agricultura familiar, tanto no Brasil quanto na região Nordeste (ESCHER et al., 2014).

Para os agricultores com pequenas propriedades e alta dependência da renda agrícola, a diversificação dentro do estabelecimento agrícola é preferível. Por exemplo, os agricultores tendem a investir em alternativas da produtividade, como conservação do solo, uso de diferentes variedades de culturas e mudança das datas de plantio, quando a principal fonte de renda é a agricultura e a quantidade de terra para a atividade é limitada (DERESSA et al., 2009). No entanto, esses agricultores são mais vulneráveis às mudanças climáticas, já que a diversificação na fonte de renda familiar ajuda a enfrentar o risco de quedas da renda, relacionadas a perdas agrícola em função de mudanças do clima (SMIT, SKINNER, 2002). 


\section{Figura 4. Renda dependente da atividade agrícola e/ou pecuária por tamanho} do estabelecimento agrícola

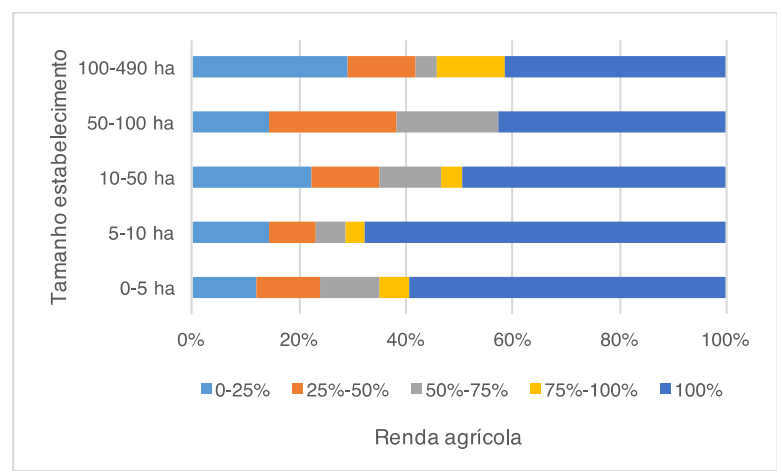

Fonte: Dados da pesquisa

Dessa forma, a diversificação com atividades fora do estabelecimento como mecanismo de adaptação na redução dos riscos advindos das mudanças climáticas está ligada não somente às características dos agricultores, mas também às políticas públicas que incentivem indiretamente a pluriatividade pelo desenvolvimento de setores de transformação.

\section{Diversificação com atividades dentro do estabelecimento agrícola}

Em média, os agricultores têm três cultivos, sendo que o número máximo é de sete cultivos. Além disso, $18,21 \%$ dos agricultores são especializados em somente um cultivo. As médias dos índices de diversificação de cultivos Herfindahl, Shannon, Margalef são, respectivamente, de 0,63; 0,64 e 0,15, indicando que os agricultores entrevistados têm baixa diversificação. No caso do índice Herfindahl, o valor obtido tende a um, o que indica perfeita especialização (um único cultivo), enquanto no caso do índice de Margalef, o valor obtido foi baixo. Esse fato pode se traduzir em vulnerabilidade agrícola frente às mudanças climáticas, dado que a bacia hidrográfica do Rio das Contas está localizada na região Nordeste, para a qual há previsão de aumento de temperatura e grandes variações nos índices pluviométricos, que podem afetar a produtividade agrícola (MARENGO et al., 2017; MAGRIN et al., 2014).

Contudo, estabelecimentos com área entre 0 a 10 hectares e mais de 100 hectares têm maior regularidade (combinação de riqueza e distribuição das 
culturas), já que, conforme seu índice ecológico Shannon de diversidade espacial, seus valores foram os maiores $(0,69)$ (Figura 3 ). Cabe destacar que os agricultores com média e grande propriedade (10 a 100 hectares) obtiveram o maior valor no índice Margalef $(0,17)$, que indica riqueza de cultivos. As grandes propriedades obtiveram o valor menor no índice de Herfindahl $(0,59)$, ou seja, são as menos especializadas. Esse fato pode estar indicando que maiores áreas agrícolas têm condições de alocar mais culturas (BENIN et al., 2004). Ademais, os valores do índice de Herfindahl indicam que os estabelecimentos com áreas médias de cultivo (10-50 hectares) tendem a ser mais especializados $(0,66)$. De forma geral, os valores dos índices não diferem muito entre os diferentes intervalos de classes de área, implicando que o tamanho da propriedade não influencia muito na decisão de diversificar as culturas na região estudada.

Foram indicadas 45 culturas produzidas pelos agricultores, na maioria dos casos, culturas de subsistência. Destacam-se entre as principais culturas o feijão e o milho (Tabela 4). Por outro lado, ao redor de $72 \%$ dos agricultores da região desenvolvem atividades relacionadas à pecuária. Entre as criações de animais com destaque, estão aves e bovinos (41\%) (Tabela 4). Em termos gerais, pode-se observar que, mesmo a diversificação de culturas sendo baixa, os agricultores complementam as atividades com a pecuária.

Figura 3. Média dos índices de diversificação de culturas por superfície total plantada para todas as culturas

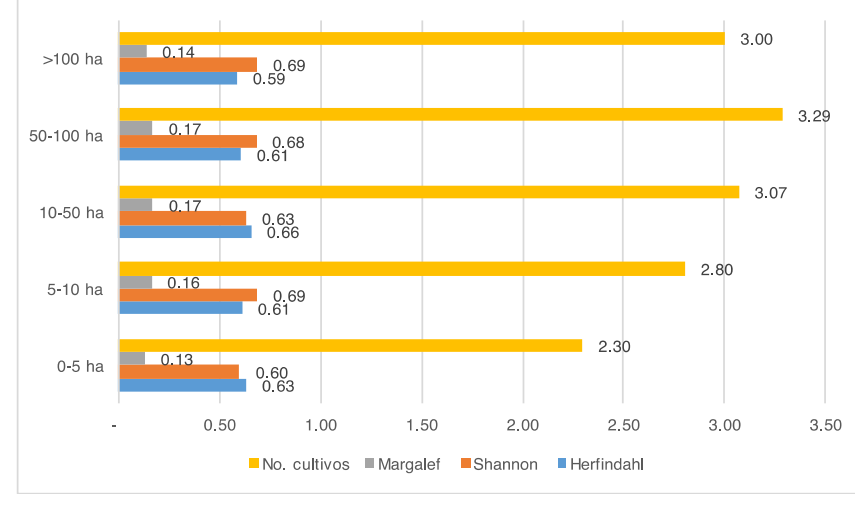

Fonte: Dados da pesquisa

Tabela 4 - Os principais cultivos e pecuária produzidos pelos agricultores entrevistados

\begin{tabular}{ccccccc}
\hline Agricultura & Feijão & Milho & Café & Pastagens & Cacau & Manga \\
\hline & $36 \%$ & $29 \%$ & $16 \%$ & $15 \%$ & $14 \%$ & $8 \%$ \\
\hline Pecuária & Aves & Bovinos & Suínos & Caprinos & Ovinos & Outros \\
\hline
\end{tabular}


Fonte: dados da pesquisa

$50 \%$

$41 \%$

$25 \%$

$5 \%$

$7 \%$

$4 \%$

\section{Determinantes da diversificação de culturas}

A Tabela 5 apresenta os resultados dos coeficientes estimadas dos três modelos de regressões. Um total de 51 observações foram censuradas, indicando os estabelecimentos especializados em uma única cultura. $O$ teste $F$ calculado foi estatisticamente significativo ao nível de $1 \%$ nos três modelos. $O$ valor da estatística LR foi significativo a $1 \%$ nos modelos, o que implica que, em conjunto, os coeficientes não são iguais a zero. Além disso, para avaliar a qualidade do ajuste dos modelos, foram aplicados testes de especificação de heterocedasticidade e normalidade dos erros para verificar a consistência, os quais rejeitaram a hipótese homocedasticidade e de normalidade. Dessa forma, os modelos Tobit foram ajustados com a matriz de White para corrigir a heterocedasticidade e evitar problemas de inconsistência (MCDONALD; NGUYEN, 2015). Por outro lado, os coeficientes de correlação entre as variáveis explicativas foram menores do que 0,8 , indicando que a multicolinearidade não é um problema grave (GUJARATI, PORTER, 2010).

Do total de 12 variáveis, quatro coeficientes foram significativamente diferentes de zero pelo menos ao nível de 10\%, em cada um dos modelos. A maioria dos sinais dos coeficientes foi semelhante nos três modelos, mostrando qualidade no ajustamento (Anexo 1). O índice Herfindahl indica concentração, portanto, um sinal negativo do coeficiente na variável explicativa implica uma relação positiva com a diversidade e vice-versa. Os coeficientes dos modelos de Tobit não podem revelar a magnitude do efeito diretamente, sendo assim, seus efeitos marginais foram estimados (Tabela 5).

Em relação ao índice de regularidade de culturas Shannon, a renda não agrícola e as características do agricultor, tais como idade, escolaridade, tamanho da família, acesso ao crédito e condição legal, não têm relação significativa com a diversificação de culturas. Entretanto, se o agricultor reside na propriedade rural, há maior incidência de diversificação de culturas, que estão distribuídas regularmente no estabelecimento. $O$ fato de morar no estabelecimento pode reduzir as exigências do tempo de transporte pelo agricultor, aumentando as oportunidades de cultivar mais espécies. Esse resultado está em consonância com a evidência empírica obtida por Benin et al. (2004). Esses autores explicam que agricultores que vivem 
mais longe de seus estabelecimentos agrícolas têm menor diversidade na cultura de cereais. Ao mesmo tempo, deve-se ressaltar que os agricultores que moram no estabelecimento diversificam as culturas para atender suas necessidades de consumo.

A assistência técnica também aumenta a adoção de mecanismos de diversificação. Em média, os agricultores que recebem esse tipo de serviço aumentam ao redor de 0,17 o nível de diversificação uniforme entre cultivos. $O$ efeito positivo da assistência técnica na diversificação é consistente com os resultados de McCord et al. (2015) e lbrahim et al. (2009).

\section{Tabela 5 - Efeitos marginais dos determinantes socioeconômicos da diversificação de culturas}

\begin{tabular}{|c|c|c|c|}
\hline Variável & $\begin{array}{l}\text { Índice } \\
\text { Margalef } \\
\text { Coeficientes }\end{array}$ & $\begin{array}{l}\text { Índice } \\
\text { Shannon } \\
\text { Coeficientes }\end{array}$ & $\begin{array}{l}\text { Índice Herfindahl } \\
\text { Coeficientes }\end{array}$ \\
\hline $\begin{array}{l}\text { Renda não agrícola } \\
(\bar{Y})\end{array}$ & $\begin{array}{c}-0,0002 \\
(0,0168)\end{array}$ & $\begin{array}{l}-0,0303 \\
(0,0686)\end{array}$ & $\begin{array}{c}0,0208 \\
(0,0340)\end{array}$ \\
\hline \multicolumn{4}{|c|}{ Características do agricultor $\left(\phi_{A}\right)$} \\
\hline Idade & $\begin{array}{l}0,00001 \\
(0,0005)\end{array}$ & $\begin{array}{c}0,0001 \\
(0.0020)\end{array}$ & $\begin{array}{c}0,000006 \\
(0,0012)\end{array}$ \\
\hline Escolaridade & $\begin{array}{l}-0,0019 \\
(0,0040)\end{array}$ & $\begin{array}{c}0,0012 \\
(0,0160)\end{array}$ & $\begin{array}{l}-0,0053 \\
(0,0092)\end{array}$ \\
\hline Tamanho da família & $\begin{array}{l}-0,0005 \\
(0,0008)\end{array}$ & $\begin{array}{l}-0,0023 \\
(0,0028)\end{array}$ & $\begin{array}{c}0,0018 \\
(0,0014)\end{array}$ \\
\hline Acesso a Crédito & $\begin{array}{l}0,0317^{* *} \\
(0,0160)\end{array}$ & $\begin{array}{c}0,0878 \\
(0,0619)\end{array}$ & $\begin{array}{l}-0,0385 \\
(0,0350)\end{array}$ \\
\hline Condição legal & $\begin{array}{l}0,0505^{\star *} \\
(0,0206)\end{array}$ & $\begin{array}{c}0,1453 \\
(0,0882)\end{array}$ & $\begin{array}{l}-0,0687 \\
(0,0513)\end{array}$ \\
\hline Moradia & $\begin{array}{l}0,0496^{\star * *} \\
(0,0161)\end{array}$ & $\begin{array}{l}0,1371^{* *} \\
(0,0653)\end{array}$ & $\begin{array}{l}-0,0699^{*} \\
(0,0378)\end{array}$ \\
\hline Assistência técnica & $\begin{array}{l}0,0325^{\star *} \\
(0,0153)\end{array}$ & $\begin{array}{c}0,1696^{\star * *} \\
(0,0597)\end{array}$ & $\begin{array}{c}-0,0929^{* * *} \\
(0,0336)\end{array}$ \\
\hline \multicolumn{4}{|c|}{ Características do estabelecimento agrícola $\left(\phi_{E A}\right)$} \\
\hline $\begin{array}{l}\text { Tamanho } \\
\text { estabelecimento } \\
\text { Irrigação }\end{array}$ & $\begin{array}{l}0,000009 \\
(0,0001) \\
-0,0210 \\
(0,0143)\end{array}$ & $\begin{array}{c}0,0001 \\
(0,0004) \\
-0,1313^{\star *} \\
(0,0590)\end{array}$ & $\begin{array}{l}-0.0001 \\
(0,0002) \\
0,0852^{* *} \\
(0,0339)\end{array}$ \\
\hline $\begin{array}{l}\text { Bioma Caatinga } \\
\text { Características do me }\end{array}$ & $\begin{array}{c}-0,0593^{* \star \star} \\
(0,0195) \\
\text { rcado }\left(\phi_{M}\right)\end{array}$ & $\begin{array}{c}-0,2629^{* * *} \\
(0,0784)\end{array}$ & $\begin{array}{l}0,1317^{* \star *} \\
(0,0441)\end{array}$ \\
\hline $\begin{array}{l}\text { Densidade } \\
\text { populacional }\end{array}$ & $\begin{array}{l}-0,0003 \\
(0,0004)\end{array}$ & $\begin{array}{l}-0,0010 \\
(0,0015)\end{array}$ & $\begin{array}{c}0,0008 \\
(0,0008)\end{array}$ \\
\hline $\begin{array}{l}\text { No. observações } \\
\text { Não censurados } \\
\text { Censurados }\end{array}$ & $\begin{array}{c}280 \\
229 \\
51\end{array}$ & $\begin{array}{c}280 \\
229 \\
51\end{array}$ & $\begin{array}{c}280 \\
229 \\
51\end{array}$ \\
\hline Média índice (ep) & $\begin{array}{c}0,1502 \\
(0,1121)\end{array}$ & $\begin{array}{l}0,6389 \\
(0,4277)\end{array}$ & $\begin{array}{c}0,6276 \\
(0,2428)\end{array}$ \\
\hline
\end{tabular}

Fonte: Dados da pesquisa (Elaborado pelos autores com o software STATA)

Nível de significância ${ }^{* \star *}=1 \%,{ }^{* *}=5 \%,{ }^{*}=10 \%$. Regressões robustas à heterocedasticidade. 
O tamanho do estabelecimento não foi significativo, mas afeta positivamente o aumento da probabilidade de diversificação regular de culturas. Esse efeito é esperado, pois a literatura relata efeitos positivos do tamanho sobre a diversificação (MCCORD et al., 2015; RAHMAN, 2008; BENIN et al., 2004).

A variável irrigação é negativa e significativa, indicando que os estabelecimentos agrícolas com irrigação têm menor probabilidade de diversificar regularmente as culturas. Diversos estudos confirmam os efeitos negativos da irrigação sobre a diversificação (MESFIN, FUFA, HAJI, 2011; RAHMAN, 2008; JOSHI et al., 2004). Esses resultados parecem indicar que a irrigação é um investimento direcionado à intensificação de cultivos.

Por outro lado, o fato de os estabelecimentos agrícolas estarem localizados no bioma da Caatinga reduz, em média, 0,26 o nível de diversificação regular. Esse resultado foi o maior efeito sobre o índice de Shannon. O bioma Caatinga é de natureza semiárida, tendo pouca precipitação e, portanto, seria pouco propício para a diversificação de culturas. Entretanto, a densidade populacional não teve influência significativa na diversificação regular de culturas.

Em relação ao índice de riqueza de culturas Margalef, os resultados foram semelhantes aos encontrados no índice de regularidade. Somente o uso de irrigação não teve relação significativa com o aumento da riqueza de espécies de culturas. Mas neste modelo $\mathrm{o}$ acesso ao crédito e $\mathrm{o}$ fato de ser proprietário do estabelecimento também foram significativos. Em média, o fato de os agricultores receberem crédito aumenta em cerca de 0,03 o nível de riqueza de culturas. $O$ acesso a linhas de crédito também é muito importante para permitir adoção de novas tecnologias que possibilitem ao produtor reduzir os riscos gerados das mudanças climáticas. Ademais, 0 fato de 0 agricultor ser proprietário do estabelecimento aumenta, em média, 0,5 o nível de riqueza de culturas. Rahman (2008) obteve resultados similares sobre a condição legal, indicando que a propriedade do estabelecimento possibilita a inovação de atividades agrícolas no longo prazo, como a diversificação de cultivos. Finalmente, os resultados no índice de concentração de culturas (Herfindahl) foram similares aos do índice Shannon, apresentado anteriormente. 


\section{Considerações Finais}

A presente pesquisa teve como foco os mecanismos de diversificação agrícola e os principais determinantes de sua adoção. A análise foi feita considerando os agricultores cujos estabelecimentos estão localizados na bacia do Rio das Contas, Bahia. A diversificação assume importância fundamental como prática de redução de riscos econômicos e ambientais, sobretudo nessa região, que é essencialmente agrícola.

De modo geral, os resultados da pesquisa indicaram que a maioria dos agricultores depende da renda agrícola ou pecuária e, dessa forma, existe pouca diversificação de atividades fora do estabelecimento. Logo, é possível afirmar que esses agricultores são mais vulneráveis às mudanças climáticas, já que a diversificação na fonte de renda familiar contribui para enfrentar os riscos relacionados à variação do clima. Da mesma forma, existe baixa diversificação dentro dos estabelecimentos agrícolas segundo os índices de diversidade de culturas. Contudo, os agricultores diversificam com atividades pecuárias. Além disso, a maioria dos agricultores da bacia hidrográfica diversifica dentro do estabelecimento, porque apenas uma quinta parte de amostra tem estabelecimentos especializados em uma única cultura. No entanto, os índices calculados indicam que essa diversificação ainda é baixa.

No que diz respeito aos determinantes da diversificação, pode-se afirmar que o acesso a linhas de créditos e assistência técnica e o fato de morar na propriedade são variáveis muito importantes. Em relação às características do estabelecimento agrícola, a ocorrência de diversificação de culturas diminui significativamente se a propriedade estiver localizada no bioma Caatinga como também se tiver irrigação.

Para finalizar, os resultados deste estudo podem ser usados para recomendar medidas políticas na adoção de estratégias de adaptação às mudanças climáticas, como a diversificação agrícola. A pesquisa sugere que essas medidas devem incluir a melhoria do acesso a facilidades de crédito e serviços de extensão/assistência técnica para os agricultores da região da bacia do Rio das Contas, Bahia. Mas para que essas medidas sejam efetivas, é importante investir em Pesquisa e Desenvolvimento de sistemas agrícolas diversificados, dadas as condições edafoclimáticas da região, de modo a ser referência para os agricultores. 


\section{REFERÊNCIAS}

ALTIERI, Miguel A. The ecological role of biodiversity in agroecosystems. Agriculture, ecosystems \& environment, v. 74, n. 1, p. 19-31, 1999.

ASFAW, Solomon; PALLANTE, Giacomo; PALMA, Alessandro. Diversification strategies and adaptation deficit: Evidence from rural communities in Niger. World Development, v. 101, p. 219-234, 2018.

ASRAVOR, Richard Kofi. Livelihood Diversification Strategies to Climate Change among Smallholder Farmers in Northern Ghana. Journal of International Development.

BELOW, Till et al. Micro-level practices to adapt to climate change for African small-scale farmers. A review of Selected Literature. Environ. Prod. Technol. Division, v. 953, 2010.

BENIN, Samuel et al. The economic determinants of cereal crop diversity on farms in the Ethiopian highlands. Agricultural Economics, v. 31, n. 2-3, p. 197-208, 2004.

BROOKFIELD, Harold; STOCKING, Michael. Agrodiversity: definition, description and design. Global environmental change, v. 9, n. 2, p. 77-80, 1999.

CARLOS, Sabrina de Matos. Percepção e adaptação às mudanças climáticas de agricultores da bacia hidrográfica do Rio das Contas, Bahia. Dissertação (Mestrado em Economia Aplicada), Universidade Federal de Viçosa, Viçosa. 2016

CEPEA. Centro de Estudos Avançados em Economia Aplicada. Produto Interno Bruto (PIB) do agronegócio. Disponível em: <http://www.cepea.esalq.usp.br> Acesso em: 26 abr. 2017.

CUNHA, Dênis Antônio da et al. Irrigação como estratégia de adaptação de pequenos agricultores às mudanças climáticas: aspectos econômicos. Revista de Economia e Sociologia Rural, v. 51, n. 2, p. 369-386, 2013.

CUNHA, Dênis Antônio; COELHO, ALEXANDRE Bragança; FÉRES, José Gustavo. Irrigation as an adaptive strategy to climate change: an economic perspective on Brazilian agriculture. Environment and Development Economics, v. 20, p. 57-79, 2015.

DASKALOPOULOU, Irene; PETROU, Anastasia. Utilising a farm typology to identify potential adopters of alternative farming activities in Greek agriculture. Journal of rural studies, v. 18, n. 1, p. 95-103, 2002.

DE LIMA, Adalto Gonçalves. A bacia hidrográfica como recorte de estudos em geografia humana. GEOGRAFIA (Londrina), v. 14, n. 2, p. 173-184, 2010.

DELCOURT, Gregg; VAN KOOTEN, G. C. How resilient is grain production to climatic change? Sustainable agriculture in a dryland cropping region of western Canada. Journal of Sustainable Agriculture, v. 5, n. 3, p. 37-57, 1995.

DERESSA, Temesgen Tadesse; Hassan, R. M.; Ringler, C.; Alemu, T. e Yesuf, M. Determinants of farmers' choice of adaptation methods to climate change in the Nile Basin of Ethiopia. Global environmental change, v. 19, n. 2, p. 248-255, 2009.

ELLIS, Frank. The determinants of rural livelihood diversification in developing countries. Journal of Agricultural Economics, v. 51, n. 2, p. 289-302, 2000. 
ESCHER, Fabiano et al. Caracterização da pluriatividade e dos plurirrendimentos da agricultura brasileira a partir do Censo Agropecuário 2006. Revista de Economia e Sociologia Rural, v. 52, n. 4, p. 643-668, 2014.

FAO - Food and Agriculture Organization. Agricultural Biodiversity, Multifunctional Character of Agriculture and Land Conference, Background Paper 1. Maastricht, Netherlands.

September 1999.

FRANCHINI, Julio Cezar et al. Integração lavoura-pecuária: alternativa para diversificação e redução do impacto ambiental do sistema produtivo no Vale do Rio Xingu. Embrapa SojaCircular Técnica (INFOTECA-E), 2010.

GLITSOS, N. P. Regional inequalities in Greece: demographic and economic features. Scientific Studies, v. 27, 1988.

GUJARATI, Damodar N.; PORTER, Dawn C. Econometria Básica-5. Amgh Editora, 2010.

IBRAHIM, H. et al. Income and crop diversification among farming households in a rural area of north central Nigeria. Journal of Tropical Agriculture, Food, Environment and

Extension, v. 8, n. 2, p. 84-89, 2009.

INCRA - Instituto Nacional de Colonização e Reforma Agrária. Tabela com módulo fiscal dos municípios. 2013. Disponível: <http://www.incra.gov.br/tabela-modulo-fiscal> Acesso em: 26 jun. 2017.

ISLAM, Nawshaba; RAHMAN, Motiur. An assessment of crop diversification in Bangladesh: a spatial analysis. Applied Economics Letters, v. 19, n. 1, p. 29-33, 2012.

JOSHI, Pramod. Diversification of Agriculture in more competitive environment. In: Ali, M. (Ed.). Asian Productivity Organization, Tokyo, Japan. 2004. Disponível: <http://www.apotokyo.org/publications/files/agr-03-ad ic.pdf> Acesso em: 14 mar. 2017

JOSHI, Pramod K. et al. Agriculture diversification in South Asia: patterns, determinants and policy implications. Economic and political weekly, p. 2457-2467, 2004.

LEAL, Inara R. et al. Mudando o curso da conservação da biodiversidade na Caatinga do Nordeste do Brasil. Megadiversidade, v. 1, n. 1, p. 139-146, 2005.

LIN, Brenda B. Resilience in agriculture through crop diversification: adaptive management for environmental change. BioScience, v. 61, n. 3, p. 183-193, 2011.

MAGRIN, G.O.; MARENGO, J.A.; BOULANGER, J.-P.; BUCKERIDGE, M.S.; CASTELLANOS, E.; POVEDA, G.; SCARANO, F.R.; VICUÑA, S. Central and South America. In: Climate Change 2014: Impacts, Adaptation, and Vulnerability. Part B: Regional Aspects. Contribution of Working Group II to the Fifth Assessment Report of the Intergovernmental Panel on Climate Change [Barros, V.R., C.B. Field, D.J. Dokken, M.D. Mastrandrea, K.J. Mach, T.E. Bilir, M. Chatterjee, K.L. Ebi, Y.O. Estrada, R.C. Genova, B. Girma, E.S. Kissel, A.N. Levy, S. MacCracken, P.R. Mastrandrea, and L.L. White (eds.)]. Cambridge University Press, Cambridge, United Kingdom and New York, NY, USA, pp. 1499-1566. 2014.

MAGURRAN, Anne E. Measuring biological diversity. Blackwell Science, 2004.

MARENGO, JOSÉ A. et al. Climatic characteristics of the 2010-2016 drought in the semiarid Northeast Brazil region. Anais da Academia Brasileira de Ciências, n. AHEAD, p. 0-0, 2017. 
MCCORD, Paul F. et al. Crop diversification as a smallholder livelihood strategy within semiarid agricultural systems near Mount Kenya. Land Use Policy, v. 42, p. 738-750, 2015.

MCDONALD, James B.; NGUYEN, Hieu. Heteroscedasticity and distributional assumptions in the censored regression model. Communications in Statistics-Simulation and Computation, v. 44, n. 8, p. 2151-2168, 2015.

MESFIN, Wondimagegn; FUFA, Bekabil; HAJI, Jema. Pattern, trend and determinants of crop diversification: empirical evidence from smallholders in eastern Ethiopia. Journal of Economics and Sustainable Development, v. 2, n. 8, p. 78-89, 2011.

MEYNARD, Jean-Marc et al. Freins et leviers à la diversification des cultures: étude au niveau des exploitations agricoles et des filières. OCL, v. 20, n. 4, p. D403, 2013. MINOT, Nicholas et al. (Ed.). Income diversification and poverty in the Northern Uplands of Vietnam. Intl Food Policy Res Inst, 2006.

MITTER, Hermine; HEUMESSER, Christine; SCHMID, Erwin. Spatial modeling of robust crop production portfolios to assess agricultural vulnerability and adaptation to climate change. Land Use Policy, v. 46, p. 75-90, 2015.

NGUYEN, Huy Quynh. Analyzing the economies of crop diversification in rural Vietnam, using an input distance function. Agricultural Systems, v. 153, p. 148-156, 2017.

RAHMAN, Sanzidur. The economic determinants of crop diversity on farms in rural Bangladesh. J. Int. Agric. Trade Dev. v. 5, p. 51-70, 2008.

SANTILLI, Juliana. Agrobiodiversidade e direitos dos agricultores. São Paulo: Petróplis, 2009.

SCHNEIDER, Sergio. A pluriatividade como estratégia de reprodução social da agricultura familiar no Sul do Brasil. Estudos sociedade e agricultura. Rio de Janeiro, RJ. N. 16 (abr. 2001), p. 164-184, 2001.

SCHNEIDER, Sergio. A importância da pluriatividade para as políticas públicas no Brasil. Revista de política agrícola, v. 16, n. 3, p. 14-33, 2007.

SIMIONI, Flávio José. Determinantes da renda familiar no espaço rural: uma revisão. Organizações Rurais \& Agroindustriais, v. 15, n. 3, 2013.

SMIT, Barry; SKINNER, Mark W. Adaptation options in agriculture to climate change: a typology. Mitigation and adaptation strategies for global change, v. 7, n. 1, p. 85-114, 2002. Disponível: <http://link.springer.com/article/10.1023/A:1015862228270> Acesso em: 26 abr. 2017.

THAMO, Tas et al. Climate change impacts and farm-level adaptation: Economic analysis of a mixed cropping-livestock system. Agricultural Systems, v. 150, p. 99-108, 2017.

VAN DEN BERG, M. Marrit et al. The impact of increasing farm size and mechanization on rural income and rice production in Zhejiang province, China. Agricultural Systems, v. 94, n. 3, p. 841-850, 2007.

VAN DUSEN, M. Eric et al. In situ conservation of crop genetic resources in the Mexican milpa system. 2000. Tese de Doutorado. University of California, Davis

WELDEGEBRIEL, Zerihun Berhane; PROWSE, Martin. Climate variability and livelihood diversification in northern Ethiopia: a case study of Lasta and Beyeda districts. The Geographical Journal, v. 183, n. 1, p. 84-96, 2017. 
Anexo 1 - Determinantes socioeconômicos da diversificação de culturas

\begin{tabular}{lccc}
\hline Variável & $\begin{array}{c}\text { Índice } \\
\text { Margalef } \\
\text { Coeficientes }\end{array}$ & $\begin{array}{c}\text { Índice } \\
\text { Shannon } \\
\text { Coeficientes }\end{array}$ & $\begin{array}{c}\text { Índice Herfindahl } \\
\text { Coeficientes }\end{array}$ \\
\hline Renda não agrícola & $-0,0002$ & $-0,0339$ & 0,0232 \\
$(\bar{Y})$ & $(0,0192)$ & $(0,0765)$ & $(0,0444)$
\end{tabular}

Características do agricultor $\left(\phi_{A}\right)$

\begin{tabular}{|c|c|c|c|}
\hline Idade & $\begin{array}{l}0,00001 \\
(0,0006)\end{array}$ & $\begin{array}{c}0,0002 \\
(0,0022)\end{array}$ & $\begin{array}{c}0,000006 \\
(0,0013)\end{array}$ \\
\hline Escolaridade & $\begin{array}{l}-0,0022 \\
(0,0046)\end{array}$ & $\begin{array}{c}0,0013 \\
(0,0179)\end{array}$ & $\begin{array}{l}-0,0059 \\
(0,0102)\end{array}$ \\
\hline Tamanho da família & $\begin{array}{l}-0,0001 \\
(0,0009)\end{array}$ & $\begin{array}{l}-0,0026 \\
(0,0031)\end{array}$ & $\begin{array}{c}0,0020 \\
(0,0015)\end{array}$ \\
\hline Acesso a Crédito & $\begin{array}{l}0,0359^{* *} \\
(0,0177)\end{array}$ & $\begin{array}{l}0,0972) \\
(0,0679)\end{array}$ & $\begin{array}{l}-0,0426 \\
(0,269)\end{array}$ \\
\hline Condição legal & $\begin{array}{l}0,0610^{\star *} \\
(0,0266)\end{array}$ & $\begin{array}{c}0,1672 \\
(0,1052)\end{array}$ & $\begin{array}{l}-0,0782 \\
(0,0430)\end{array}$ \\
\hline Moradia & $\begin{array}{l}0,0579^{\star * *} \\
(0,0192)\end{array}$ & $\begin{array}{l}0,1548^{\star \star} \\
(0,0748)\end{array}$ & $\begin{array}{c}-0,0785^{\star *} \\
(0,0430)\end{array}$ \\
\hline Assistência técnica & $\begin{array}{l}0,0368^{\star *} \\
(0,0172)\end{array}$ & $\begin{array}{c}0,1869^{* \star *} \\
(0,0653)\end{array}$ & $\begin{array}{c}-0,1021^{* * *} \\
(0,0366)\end{array}$ \\
\hline \multicolumn{4}{|c|}{ Características do estabelecimento agrícola $\left(\phi_{E A}\right)$} \\
\hline $\begin{array}{l}\text { Tamanho } \\
\text { estabelecimento } \\
\text { Irrigação }\end{array}$ & $\begin{array}{l}0,000009 \\
(0,0001) \\
-0,0242 \\
(0,0167)\end{array}$ & $\begin{array}{c}0,0015 \\
(0,0004) \\
-0,1479^{* *} \\
(0,0676)\end{array}$ & $\begin{array}{c}0.0001 \\
(0,0002) \\
0,0956^{\star *} \\
(0,0387)\end{array}$ \\
\hline $\begin{array}{l}\text { Bioma Caatinga } \\
\text { Características do }\end{array}$ & $\begin{array}{c}-0,0667^{\star \star \star *} \\
(0,0215) \\
\text { ado }\left(\phi_{M}\right)\end{array}$ & $\begin{array}{c}-0,2886^{* * *} \\
(0,8446)\end{array}$ & $\begin{array}{c}0,1443^{* * *} \\
(0,0477)\end{array}$ \\
\hline $\begin{array}{l}\text { Densidade } \\
\text { populacional }\end{array}$ & $\begin{array}{c}0,0003 \\
(0,0004)\end{array}$ & $\begin{array}{l}-0,0012 \\
(0,0016)\end{array}$ & $\begin{array}{c}0,0009 \\
(0,0009)\end{array}$ \\
\hline Constante & $\begin{array}{c}0,0787 \\
(0,0523)\end{array}$ & $\begin{array}{c}0.5559^{\star \star *} \\
(0,2081)\end{array}$ & $\begin{array}{c}0,6600^{* * *} \\
(0,1177)\end{array}$ \\
\hline $\begin{array}{l}\text { No. observações } \\
\text { Não censurados } \\
\text { Censurados }\end{array}$ & $\begin{array}{c}280 \\
229 \\
51\end{array}$ & $\begin{array}{c}280 \\
229 \\
51\end{array}$ & $\begin{array}{c}280 \\
229 \\
51\end{array}$ \\
\hline $\begin{array}{l}\text { Teste } F_{(12,246)} \\
\text { LR } X^{2}(12) \\
\text { Pseudo } R^{2} / R^{2}\end{array}$ & $\begin{array}{l}3,30^{* * *} \\
48,30^{\star * *} \\
-0,2947\end{array}$ & $\begin{array}{c}3,26^{* * *} \\
40,94^{\star * *} \\
0,0897\end{array}$ & $\begin{array}{c}2,95^{\star * *} \\
35,11 \\
0,1769\end{array}$ \\
\hline
\end{tabular}

Fonte: Dados da pesquisa (Elaborado pelos autores com o software STATA)

Nível de significância ${ }^{* * *}=1 \%,{ }^{* *}=5 \%,{ }^{*}=10 \%$. Regressões robustas à heterocedasticidade.

\section{NOTAS DE AUTOR}

\section{CONTRIBUIÇÃO DE AUTORIA}

Elena Beatriz Piedra-Bonilla - Concepção. Análise de dados, Elaboração do manuscrito, revisão e aprovação da versão final do trabalho

Dênis Antônio da Cunha - Coleta de dados. Elaboração do manuscrito. Participação ativa da discussão dos resultados; Revisão e aprovação da versão final do trabalho.

Marcelo José Braga - Participação ativa da discussão dos resultados; Revisão e aprovação da versão final do trabalho.

\section{FINANCIAMENTO}

O presente trabalho foi realizado com apoio da Coordenação de Aperfeiçoamento de Pessoal de Nível Superior Brasil (CAPES) - Código financeiro 001 (bolsa de doutorado para o autor EBPB). O autor DAC agradece o apoio 
financeiro do Conselho Nacional de Desenvolvimento Científico e Tecnológico - CNPq (Processos número: 305807/2018-8 e 408382/2013-9) e da Fundação de Amparo à Pesquisa do Estado de Minas Gerais - FAPEMIG (PPM-00022-14). O autor MJB agradece ao CNPq a Bolsa de Produtividade em Pesquisa - Nível 1C.

\section{CONSENTIMENTO DE USO DE IMAGEM}

Não se aplica

\section{APROVAÇÃO DE COMITÊ DE ÉTICA EM PESQUISA}

A pesquisa foi provada pelo Comitê de ética em pesquisa com seres humanos da Universidade Federal de Viçosa. Número de processo: 713.698; data: 9/07/2014.

\section{CONFLITO DE INTERESSES}

Não se aplica

\section{LICENÇA DE USO}

Este artigo está licenciado sob a Licença Creative Commons CC-BY. Com essa licença você pode compartilhar, adaptar, criar para qualquer fim, desde que atribua a autoria da obra.

\section{HISTÓRICO}

Recebido em: 11-07-2018

Aprovado em: 11-05-2019 